\title{
¿SABER SIN VERDAD? OBJECIONES A UN ARGUMENTO DE VILLORO*
}

\author{
Guillermo HuRTADo \\ Instituto de Investigaciones Filosóficas \\ Universidad Nacional Autónoma de México \\ gmhp@servidor.unam.mx
}

RESUMEN: Se examina uno de los argumentos principales de Creer, saber, conocer en contra de la inclusión de la noción de verdad en la definición de saber. Se sostiene que el argumento falla, entre otras razones, porque concede al escéptico una premisa falsa acerca de las condiciones de aplicabilidad del verbo "saber".

PALABRAS CLAVE: saber, verdad, Luis Villoro

SUMMARY: One of the main arguments of Creer, saber, conocer against the inclusion of the notion of truth in the definition of knowledge is examined. It is claimed that the argument fails, among other reasons, because it grants the sceptic a false premise about the conditions of applicability of the verb "to know".

KEY WORDS: knowledge, truth, Luis Villoro

1. En Creer, saber, conocer se sostiene que saber que $p$ es creer que $p$ y tener razones objetivamente suficientes para ello (1989, p. 175). Una razón es objetivamente suficiente si es concluyente, completa y coherente con independencia de quien la sustente; sin embargo, una razón en particular puede ser objetivamente suficiente en una comunidad epistémica sin serlo en otras. De esto se desprende, por ejemplo, que Alfonso X sabía que la Tierra está en el centro del Universo, ya que, aunque su creencia era falsa, sus razones eran objetivamente suficientes. Ahora bien, lo normal no es decir que Alfonso X sabía que la Tierra ocupa el centro del Universo, sino que creía saberlo (Cfr. Moulines 1993). No obstante, Villoro asume el relativismo epistémico como una consecuencia de su teoría. En un pasaje de Creer, saber, conocer, él justifica su relativismo con esta disyuntiva dramática: "O no hay saber o todo saber está condicionado

*Este ensayo crítico sobre Creer, saber, conocer está dedicado con afecto al autor de dicho libro. 
socialmente. La historicidad del saber es la única alternativa válida frente al escepticismo" (1989, p. 164).

Villoro no es, sin embargo, un asambleísta epistémico. La noción de razón objetivamente suficiente no implica que para que $S$ sepa que $p$ deba haber un consenso en su comunidad. Villoro afirma que puede ser que en una comunidad epistémica no haya más que un sujeto epistémico pertinente para juzgar de la verdad de una determinada creencia $(1989$, p. 152). Pero si las razones de este único sujeto son, en efecto, objetivamente suficientes, cualquiera que en su comunidad epistémica las comprendiera y aquilatara habría de coincidir con ellas y así podría generarse un consenso. Hay que tener en claro que Villoro jamás desliga el concepto de objetividad del concepto de verdad. Por tanto, sería un error suponer que él expulsa la noción de verdad de la epistemología. Como hemos visto, una justificación es objetiva si se da en una comunidad epistémica concreta. Pero Villoro afirma que la noción de "verdad" y su correlativa de "realidad" son indispensables para comprender la noción de objetividad y, en particular, para explicar la objetividad de la justificación. La mejor explicación de la coincidencia de juicios en una comunidad epistémica, afirma él, es la existencia real, independiente de los sujetos, de los hechos juzgados. $(1989$, p. 181). Y es que a pesar de su relativismo epistémico, Villoro no es un realista ortodoxo respecto a las fuentes de la objetividad. Es más, yo diría que este realismo es patente desde el capítulo tercero de Creer, saber, conocer, ya que allí define la creencia como un estado de disposición para actuar determinado por un objeto o una situación del mundo, i.e. de un mundo independiente.

Sin embargo, no debemos equivocarnos respecto al divorcio tajante que hace Villoro entre los conceptos de saber y de verdad. Villoro acepta que alguien sepa sin que su creencia sea verdadera. A esto lo llama saber falible. Cuando afirma que la noción de "razón objetivamente suficiente" no puede entenderse sin la noción realista de verdad, no dice que una condición necesaria para que las razones de $S$ para creer que $p$ sean objetivamente suficientes es que $p$ sea verdadera; lo que 
dice es que la inteligibilidad de la noción de objetividad supone la de verdad, pero no está volviendo a introducir, de una manera indirecta, la verdad en el análisis de la noción de saber. A mí me parece que aunque Villoro no caiga en una contradicción obvia es, por lo menos difícil aceptar, por una parte, que no podemos comprender el concepto de objetividad sin el de verdad y, por otra, que se pueden tener razones suficientemente objetivas para creer que $p$ sin que esa $p$ sea verdadera. Esta tensión teórica — por llamarla de algún modo - fue, me parece, la que motivó la polémica de León Olivé (1984) y Ana Rosa Pérez Ransanz (1993) con Villoro. Lo que ellos proponían es que él desligara el concepto realista de verdad del de objetividad, que acabara de expulsarlo de la epistemología.

Yo quisiera, tomando en cuenta esta misma tensión teórica, defender lo contrario: que la íntima relación entre los conceptos de objetividad y verdad es un reflejo de la conexión real e insoslayable del concepto de saber con el de verdad planteada por la definición tradicional. Villoro describe su análisis de saber como una reforma de dicho concepto, ya que, según concede, su análisis no coincide con nuestro uso de la palabra "saber". A mí me parece que la gravedad de este hecho es mayor de la que acaso le concede Villoro. Es más, creo que en el análisis de los diversos usos cotidianos de "saber" que ofreció en el capítulo 6 de Creer, saber, conocer - y años antes en un importante ensayo (Villoro 1969) - e incluso en el examen de la noción de creencia que propone en el capítulo 3 de ese mismo libro, tenemos los elementos para mostrar que los conceptos de saber y de verdad no pueden desligarse, como propone en el capítulo 8 de su libro. El problema, en mi opinión, consiste en que no interpretó adecuadamente los datos sobre el uso de "saber" que ofreció en el capítulo 6. Mi sospecha es que, a pesar de todo, Villoro sigue moviéndose en un terreno cercano al del escéptico y que eso es lo que, a fin de cuentas, lo lleva al relativismo epistémico.

En lo que sigue haré una lectura crítica del primero de los tres argumentos para eliminar la verdad de " $p$ " del análisis de " $S$ sabe que $p$ " que Villoro ofrece en la tercera sección del capítulo 8 de Creer, saber, conocer. Un estudio a fondo del libro 
habría de tomar en cuenta el segundo y el tercer argumentos. Sin embargo, creo que el examen de este primer argumento - acaso el de mayor importancia de los tres - ofrece suficientes elementos que apuntan hacia la interpretación del libro que he sugerido. Si en efecto el rechazo que hace Villoro de la definición tradicional de saber carece de bases sólidas, habrá que hacer una revisión crítica de todo el sistema epistemológico de Creer, saber, conocer y quizá incluso de algunas de las propuestas que hace Villoro en ese otro libro espléndido que es El poder y el valor.

2. El argumento que nos ocupa no es sencillo, por lo que, antes de criticarlo, hay que exponerlo con cuidado. Villoro comienza por señalar que en la segunda cláusula de la definición tradicional de saber, la que reza que $p$ es verdadera, no se señala quién juzga que $p$ sea verdadera. Ante esto podemos considerar las siguientes tres posibilidades:

1. Que la proposición " $p$ es verdadera" de la segunda cláusula de la definición de " $S$ sabe que $p$ " es aseverada por $S$.

2. Que " $p$ es verdadera" es aseverada por otro sujeto.

3. Que " $p$ es verdadera" no es aseverada por nadie.

Supongamos que sea $S$ quien asevera la verdad de $p$. Si esto es así, nos dice Villoro, " $p$ es verdadera" no es condición de " $S$ sabe que $p$ ". Esto se debe a que, según él, $S$ juzga la verdad de $p$ con base en su juicio de que él tiene razones suficientes para creer que $p$. Pero " $S$ juzga tener razones suficientes para creer que $p$ " es una condición de "S está cierto de $p$ " no de " $S$ sabe que $p$ ", puesto que otro sujeto puede juzgar que sus razones son insuficientes.

Supongamos entonces que " $p$ es verdadera" es aseverada por cualquier otro sujeto pertinente. Pero esto es otra manera de decir, afirma Villoro, que las razones de $S$ para creer que $p$ no sólo son suficientes, sino que son "objetivamente suficientes"; es decir, son suficientes para cualquier otro sujeto epistémico pertinente. Y eso es lo que dice expresamente la segunda condición del análisis de " $S$ sabe que $p$ " que él propone, por lo 
que la segunda condición del análisis tradicional - i.e. " $p$ es verdadera" - saldría sobrando.

Sólo resta considerar la posibilidad de que " $p$ es verdadera" no sea aseverada por alguien, sino que lo que hace es simplemente expresar que el hecho $p$, al que se refiere la creencia, existe en la realidad, con independencia de cualquier sujeto. Pero interpretada la verdad como verdad absoluta, es decir, como independiente de las razones aducidas en una de las dos posibilidades anteriores, no puede aplicarse, según Villoro, a ningún juicio de un sujeto. Sin las razones de algún sujeto, no puede juzgarse si una proposición es verdadera y, por tanto, si alguien que cree en ella sabe.

Villoro concluye que si la segunda condición de la definición tradicional es independiente de la tercera - como cuando " $p$ es verdadera" no es juzgada por nadie - resulta inaplicable a cualquier proposición o sujeto. Para que la segunda condición sea aplicable no debe ser independiente de la tercera - como cuando " $p$ es verdadera" es juzgada por otros sujetos. Para que el concepto de saber sea aplicable hay que eliminar la segunda condición de la definición tradicional y modificar la tercera condición añadiendo la objetividad como un requisito de las razones suficientes esgrimidas por $S$ en favor de $p$.

3. Comencemos por considerar el dato - que a Villoro le resulta intrigante - de que en el análisis tradicional de saber no se dice quién $S$ asevera que $p$ es verdadera.

Si por aseverar que $p$ se entiende la expresión verbal o la enunciación escrita de " $p$ " o de " $p$ es verdadera", es sencillamente falso que una condición necesaria para que $S$ sepa que $p$ sea que él o alguien más asevere que $p$ o que $p$ es verdadera. Es un hecho que sabemos cosas de las que jamás hemos hablado y de las que jamás hablaremos. Sin embargo, podemos entender algo más débil por "aseverar que $p$ ", digamos el hecho de que en algunas circunstancias sostendríamos la verdad de $p$. Pero sospecho que ni siquiera esto vale en todos los casos. Hay quien sabe cosas cuya verdad jamás defendería en público — secretos que se llevan a la tumba. Me parece, por lo tanto, que la mejor manera de entender qué es aseverar que $p$ en el contexto de 
la definición de saber es afirmar que una condición para saber que $p$ es creer que $\mathrm{p}$ es verdadera. Y esto es lo que parece tener en mente Villoro cuando pregunta quién es el que juzga que $p$ es verdadera en la segunda cláusula de la definición tradicional de saber.

Villoro sostiene que se puede saber que $p$ sin que $p$ sea verdadera. ¿Se puede saber que $p$ sin creer (juzgar o aseverar) que $p$ sea verdadera? A mí me parece que para que $S$ sepa que $p, S$ ha de creer que $p$ es verdadera. Imaginemos el siguiente diálogo:

$a$ : Escúchame, yo sé que $p$.

$b$ : Ah, vaya, entonces tú crees que $p$ es verdadera.

$a$ : No, más bien creo que $p$ es falsa.

La posición de $a$ resulta absurda. Él no puede decir que sabe que $p$ sin decir también que cree que $p$ es verdadera, es decir, que lo que expresa $p$ se da en la realidad; lo cual no implica - como veremos más adelante - la tesis más fuerte de que una condición para decir que uno sabe que $p$ es que $p$ sea de hecho verdadera o la tesis, no menos fuerte, de que una condición para decir que uno sabe que $p$ es que no se tengan dudas acerca de la verdad de $p$ (siempre y cuando, claro, esas dudas no sofoquen la creencia).

Si bien creer que $p$ es una condición para decir que se sabe que $p$, podemos afirmar lo mismo respecto al hecho mismo de saber que $p$. Uno puede creer algo por un acto de voluntad, por ejemplo cuando alguien quiere creer que un moribundo se salvará aunque sabe que está al borde de la muerte. Pero cuando la creencia no está determinada por un deseo o un miedo o por algo parecido, cuando la creencia es una actitud epistémica plena, todo indica que se cree lo que se supone como verdadero, no lo que se piensa que es falso. El saber, por lo tanto, está orientado hacia la verdad porque la creencia misma ya lo está. Creer que $\mathrm{p}$ es creer que $\mathrm{p}$ es un hecho, es decir, que $\mathrm{p}$ es verdadera. Por lo tanto, si para saber que $\mathrm{p}$ hay que creer que $\mathrm{p}$, para saber que $\mathrm{p}$ hay que creer que $\mathrm{p}$ es verdadera. Este dato conceptual tan básico debe bastar para que nos percatemos de 
que el divorcio que hace Villoro de las nociones de saber y de verdad no puede ser correcto.

En la definición de creencia que se ofrece hacia el final del capítulo 3 de Creer, saber, conocer no se sostiene que una condición para que $S$ crea que $p$ es que $S$ tome a $p$ como verdadera; sin embargo, se incorpora la noción de verdad en dicha definición, aunque no de manera explícita. Según Villoro $S$ cree que $p$ si y sólo si $S$ está en un estado adquirido $x$ de disposición a responder de determinada manera ante variadas circunstancias, $p$ ha sido aprehendida por $S$ y $p$ determina $x$. No aparece el concepto de verdad en esta definición — como sí lo está en la definición de Braithwaite (1967), examinada por Villoro, en la que una de las cláusulas es que " $S$ tiene una disposición a actuar como si $p$ fuera verdadera"-, pero Villoro mismo sostiene que en su definición se puede hallar la verdad en la cláusula que sostiene que $x$, i.e. la creencia, está determinada por $p$; es decir, por el objeto o la situación objetiva a la que hace referencia la creencia (p. 72). Podemos entonces ver que la definición de creencia ofrecida en Creer, saber, conocer está en tensión con la definición de saber propuesta unos capítulos más adelante en el mismo libro. No se puede incorporar la verdad en el análisis de la creencia, aunque sea de manera oblicua, y descartarla posteriormente en el análisis del saber. ${ }^{1}$

4. En el argumento de Villoro que aquí nos ocupa se afirma que el que $S$ crea (i.e. juzgue) la verdad de $p$ no es condición de que $S$ sepa que $p$, sino de que $S$ esté cierto de $p$. Para entender esto hay que recordar las conclusiones del capítulo 6 de Creer, saber, conocer. En ese capítulo se distinguen dos sentidos de creer: uno - el sentido fuerte - es el de estar cierto o estar seguro; el otro - el sentido débil- es el de tener una presunción o suposición. Cuando uno está cierto de que $p$, cree que sabe $p$.

${ }^{1}$ Jesús Mosterín (1993) ha observado que Villoro no contempla la distinción entre creer y aceptar que ha sido trazada, entre otros, por J. Cohen (1992). Es posible que algunas de las tesis de Villoro que aquí critico cobren más fuerza si se reinterpretan como tesis no acerca de la creencia y su relación con el saber, sino acerca de la aceptación y su relación con el saber (y, en especial, con la racionalidad práctica). Esta posibilidad me parece digna de consideración pero no me ocuparé aquí de ella por razones de espacio. 
Cuando uno tiene una presunción de $p$, no cree que sabe $p$. Cuando uno está cierto de $p$, cree que $p$ es verdadero. Cuando uno tiene una presunción de $p$, cree que $p$ podría resultar ser falsa.

Ahora bien, ¿qué diferencia hay entre estar cierto y saber? Para responder esta pregunta, Villoro considera por separado los casos de la primera persona y de la tercera persona.

En el primer caso, Villoro parte del dato de que en la primera persona de presente de indicativo "saber" significa "estar cierto". Para distinguir entre ambos significados hay que hacerlo desde la tercera persona o hay que considerar, desde la primera persona, al presunto saber desde un tiempo posterior. Dice Villoro:

para distinguir entre "saber" y "estar cierto" es menester que "saber" pueda rebasar mi creencia actual. En sentido estricto, sólo tienen un saber distinto de su certeza los otros o yo en mi pasado, pero no en mis creencias actuales. Que "saber" signifique algo más que "estar cierto" supone una situación comunitaria en que varios sujetos, o yo mismo en varios momentos, pueden comprobar lo mismo. (Villoro 1989, p. 141)

En respuesta a Villoro podríamos decir que si tomamos en serio su afirmación de que "en sentido estricto no hay saber en las creencias actuales", habría que rechazar que una condición para saber que $p$ sea creer que $p$ en presente y que sólo se puede saber aquello que se ha dejado de creer. Pero Villoro no llega tan lejos. Me parece que lo que él debió haber dicho es que para saber que $p$ no basta con estar cierto de que $p$. Pero de lo anterior no se sigue que para que $S$ sepa que $p$ no tenga que creer que $p$ o no deba creer que $p$ es verdadera. Si $p$ no creyese que $p$ es verdadera, no se entendería que cuando $S$ afirma que sabe que $p, S$ esté dispuesto a que otros o él mismo comprueben la verdad de $p$. Villoro no negaría lo anterior, pero lo que diría es que esto es otra manera de afirmar que, para que $S$ sepa que $p-\mathrm{y}$ no sólo esté cierto de $p-$, sus razones deben ser objetivas. 
Para que nuestras razones para saber sean objetivas deben estar en dos planos que se cruzan: el del mundo tal como es, i.e. el de la transubjetividad, y el del espacio público de las razones, i.e. el de la intersubjetividad. Pero parece que Villoro a veces pierde de vista que la primera es una condición de la segunda y, hasta cierto punto, independiente de ella. Otros sujetos pueden determinar que yo sé o yo sabía, porque pueden comprobar que lo que creo o creía en sentido fuerte es o era verdadero. Pero como Villoro mismo reconoce, puedo determinar si sabía algo sin necesidad de otros sujetos, es decir, de testigos o jueces. Lo único que tengo que hacer es comprobar por mí mismo que mi creencia haya sido verdadera o lo siga siendo.

Es importante recalcar el hecho de que el uso cotidiano de "saber" supone que podamos comprobar que nuestra creencia es verdadera. Si esta práctica de comprobación fuese irrealizable, la práctica de uso del término "saber" también sería vacua. Éste es el núcleo de un posible argumento contra el escéptico basado en el análisis del uso de "saber" que Villoro esboza en el capítulo 6 de su libro. Ahora quisiera considerar con mayor atención el dato de que el sujeto - i.e. el hablante que utiliza el término "saber" - puede comprobar la verdad de su creencia y, por tanto, puede determinar, él solo, si su creencia es un saber.

Como ejemplo tomemos el de Cristóbal Colón divisando la costa de lo que hoy se llama América. En ese instante, Colón comprobó que su creencia de que llegaría a tierra firme navegando hacia el poniente era verdadera y que, por tanto, esa creencia — basada en razones accesibles y comprensibles para otros miembros pertinentes de su comunidad epistémica- era un saber. (Podría decirse, claro, que su creencia de que había llegado a Asia era falsa, pero ésa sería otra creencia y otro ejemplo.) La comprobación de aquella creencia fue resultado de una empresa colectiva, pero habría sido la misma si el genovés hubiese estado solo al final de su viaje. Colón, antes de partir, le habría dicho a Isabel de Castilla que él sabía que había tierra cruzando el Atlántico. Colón no podría decir que sabía aquello si no creyera fervientemente que su creencia era verdadera, si no creyera que él sabía. Esto no era, por supuesto, garantía 
de que él supiera, por eso los que lo patrocinaron arriesgaron. En ese momento, como diría Villoro, no había manera objetiva y pública de distinguir entre el hecho de que Colón estuviera cierto de que había tierra allende el océano y el hecho debatible de que lo supiera. Cuando Colón divisó en lontananza la isla de Salvador, comprobó que sí sabía. Y no lo comprobó por revisar una vez más sus razones o por discutir acerca de ellas con otros miembros de su comunidad epistémica; supo que sabía porque vio la tierra firme con sus propios ojos, porque desembarcó en ella. Por lo tanto, para saber que $p$ hay que creer que $p$ es verdadera y si bien puede no haber manera en el uso en presente indicativo del verbo "saber" de distinguir entre estar cierto y saber, es posible, en otro momento, comprobar que se sabía porque es posible comprobar que $p$ es verdadera, y para llevar a cabo esta comprobación no hace falta que otros la avalen en ese momento, aunque sí debe ser posible que lo hubieran hecho en ese momento o que lo hagan en otro posterior. Y no se busque en este ejemplo una suerte de defensa del subjetivismo, o del fundacionismo o del tan manido mito de lo dado. No. Yo diría que no hay teoría aquí. Es así como usamos el verbo "saber" y punto.

5. Examinemos ahora el argumento que ofrece Villoro en contra de que la cláusula $p$ es verdadera, no juzgada por nadie, sea una condición de saber. La razón que se aduce, como ya vimos, es que si la verdad de $p$ fuera una condición de saber que $p$, el concepto de saber sería inaplicable.

Villoro sostiene que una cosa es afirmar que la verdad de $p$ es independiente de cualquier sujeto, que afirmar que la verdad de $p$ pueda ser juzgada o sabida con independencia del juicio de cualquier sujeto. Para saber si alguien sabe es preciso saber si lo que cree es verdadero, pero para saber esto no disponemos más que de las razones que tenemos en cada momento. Nuestro único criterio de verdad son las razones objetivamente suficientes y éstas son irremediablemente falibles. Cito a Villoro:

la justificación objetiva, aunque sea la más fuerte garantía que podamos tener de las verdades empíricas, no las implican con 
necesidad, porque es relativa al número de razones accesibles a una comunidad epistémica y éstas están empíricamente condicionadas. Nunca podremos tener una seguridad absoluta de que no pudiera haber razones para otra comunidad, a las que no podemos tener acceso, que revocaran nuestro actual saber acerca de hechos empíricos. (Villoro 1989, p. 180)

Tenemos ya los elementos para comprender por qué Villoro rechaza el análisis tradicional del saber y por qué dijo que el relativismo es la única opción frente al escepticismo.

El razonamiento de Villoro, si lo entiendo correctamente, es el siguiente. No podemos acceder a la verdad más que por medio de las razones que tenemos en cada momento. Pero si aceptamos que somos falibles, es decir, que nuestras mejores razones el día de hoy pueden ser revocadas por otras razones el día de mañana, entonces el escéptico podría decir que como nunca tenemos una seguridad absoluta de que sabemos que sabemos nunca podríamos decir que sabemos. Pero entonces $-\mathrm{y}$ esto es lo que le preocupa a Villoro - el concepto de saber sería inaplicable. Su solución es redefinir radicalmente el concepto de saber, hacerlo aplicable frente al reto escéptico, es decir, sostener que para saber que $p$ no es preciso la verdad absoluta de $p$, sino que basta con que se tengan razones objetivamente suficientes en nuestra comunidad epistémica. De esta manera, podremos seguir aceptando que el día de mañana cualquiera de nuestros saberes pueda ser corregido, pero que, el día de hoy, podemos decidir si sabemos o no, es decir, que disponemos de un criterio aplicable del concepto saber.

El argumento de Villoro, sin embargo, acepta la premisa del escéptico de que para aplicar el concepto de saber hay que tener un criterio seguro para saber que se sabe. Pero si negáramos esta premisa, bloquearíamos el reto escéptico y, por lo mismo, el paso hacia el relativismo epistémico sería innecesario.

El uso en presente de "saber" no implica que en el futuro no podamos decir en primera o tercera persona: "Estaba equivocado. No sabía." La regla de uso del verbo "saber" permite afirmar que uno sabe que p aunque p resulte ser falsa (lo que no implica que uno sepa, sino únicamente que es válido hacer 
esa afirmación falsa). ${ }^{2}$ Por lo tanto, lo que nos pide el escéptico va en contra de la regla de uso de "saber". Lo que nos pide es que "saber" tenga otro significado; i.e. que el uso presente de "saber" incluya elementos que garanticen que en un futuro no nos veamos en la situación de decir "Estaba equivocado. No sabía."*

Pero si la exigencia del escéptico es inaceptable por ir en contra la regla de uso de "saber", lo mismo podemos decir acerca de la redefinición del concepto de saber que propone Villoro. Si Alfonso X hubiera descubierto que su creencia geocéntrica era falsa, él pudo haber dicho, de acuerdo con la definición de saber de Villoro, algo tan peregrino como: "Ahora sé que la tierra no es el centro del universo, pero antes yo sabía que la tierra está en el centro del universo." Esto no es lo que diría un hablante normal y menos alguien con la modestia que suponemos tenía el sabio rey. (Lo que él pudo haber dicho, sin embargo, es que su afirmación falsa de que sabía aquello no violaba la regla de uso de "saber".) Por lo tanto, cuando Villoro exige un concepto aplicable de saber, comete, sin percatarse de ello, el mismo error del escéptico: exigir o echar de menos un criterio para determinar, en cada caso y de inmediato, cuándo alguien que dice que sabe sabe y cuándo no. Pero ésa no es una exigencia aceptable ya que, como he dicho, va contra la regla de uso de "saber". Afirmar que uno sabe, en presente, es como hacer una apuesta pública a favor de la verdad de lo creído, es solicitar a los demás que confíen en las razones que ofrecemos a favor de la verdad de lo creído. La apuesta puede ser exitosa - en cuyo caso se dictaminaría que sabíamos cuando afirmábamos saber y que sabíamos porque nuestra creencia era

${ }^{2}$ Se podría objetar que no he probado que haya una "regla de uso" del verbo "saber" y que lo que digo acerca de ella es poco. Creo, sin embargo, que aunque no hubiera una sino varias reglas o no hubiera ni siquiera algo que pudiéramos llamar con propiedad una regla, podríamos, a partir de la observación del significado de saber (o de uno de sus significados centrales) extraer la conclusión que pretendo. En todo caso, por razones de espacio me veo obligado a dejar de lado el examen de esta importante cuestión.

*Agradezco a Leticia Chaurand por las esclarecedoras conversaciones que hemos tenido acerca de este punto. 
justificada y verdadera- o puede no serlo, y en ese caso diríamos que no sabíamos. Y para determinar si la apuesta fue o no exitosa lo que hacemos es sencillamente comprobar - a veces de manera colectiva y otras veces, como hemos visto, de manera solitaria - si la creencia en cuestión se apegaba a los hechos, es decir, si era o no verdadera. Y no hay nada misterioso en ello. Sólo un escéptico pone en duda que a veces puede comprobarse la verdad de nuestras creencias con tan sólo abrir los ojos.

No se halla aquí, por tanto, una razón sólida para divorciar - como pretende Villoro, movido por el escéptico- el concepto de saber del de verdad. Puede aceptarse, por una parte, que el concepto de saber es perfectamente aplicable - porque lo es de manera cotidiana - y, por otra parte, que lo que hoy pasa por saber mañana se juzgue como creencia falsa, sin tener que rechazar la íntima liga entre los conceptos de saber y verdad. ${ }^{3}$

\section{BIBLIOGRAFÍA}

Braithwaite, R.B., 1967, "The Nature of Believing", en A. Phillips Griffiths, Knowledge and Belief, Oxford University Press, Londres, pp. 28-40.

Cohen, L.J., 1992, An Essay on Belief and Acceptance, Clarendon Press, Oxford.

${ }^{3}$ Acabo con una apostilla sobre el falibilismo, que es la otra premisa del argumento de Villoro que hemos examinado aquí y que también es una premisa explícita — y central— del siguiente argumento que él ofrece contra la definición tradicional de saber en el capítulo 8. No es claro hasta qué punto es Villoro un falibilista en Creer, saber, conocer. En ocasiones sostiene que todo conocimiento empírico es falible y en otras que podemos tener la seguridad de que la mayoría de nuestros saberes ordinarios jamás serán corregidos (p. 194). En el argumento que he examinado aquí y en el siguiente que se ofrece en el capítulo 8, Villoro sostiene, sin embargo, un falibilismo fuerte. En otro sitio (Hurtado 2000) he intentado probar que no sólo carecemos de razones para aceptar un falibilismo fuerte como el que esgrime Villoro, sino que esta doctrina es contraria al sentido común y, a la larga, dialécticamente débil frente al escepticismo y al dogmatismo. Es razonable suponer que muchas de nuestras creencias son falsas, pero no que cualquiera de ellas puede serlo. En consecuencia, yo también rechazaría la premisa falibilista de los argumentos de Villoro en contra de la definición tradicional de saber. 
Garzón Valdés, E. y F. Salmerón (comps.), 1993, Epistemología y cultura: en torno a la obra de Luis Villoro, Instituto de Investigaciones Filosóficas-UnAM, México.

Hurtado, G., 2000, "Por qué no soy falibilista", Crítica, vol. XXXII, no. 96 , pp. $59-57$.

Mosterín, J., 1993, "Dos notas sobre la racionalidad", en Garzón Valdés y Salmerón 1993, pp. 87-93.

Moulines, C.U., 1993, "Platonismo vs. relativismo en la teoría del saber", en Garzón Valdés y Salmerón 1993, pp. 11-22.

Olivé, L., 1984, "Villoro sobre objetividad, verdad y saber", Crítica, vol. XVI, no. 48, pp. 79-103.

Pérez Ransanz, A.R., 1993, "El realismo de Villoro", en Garzón Valdés y Salmerón 1993, pp. 39-62.

Villoro, L., 1997, El poder y el valor, Fondo de Cultura Económica, México.

1989, Creer, saber, conocer, Siglo XXI, México.

1969, "De la distinción entre estar cierto y saber", Crítica, vol. III, no. 9, pp. 33-58.

Recibido el 17 de marzo de 2003; aceptado el 7 de mayo de 2003. 